\title{
An Analysis Of Firm Level Auditor Tenure On Audit Hours
}

\author{
Willie E. Gist, Ohio University, USA
}

\begin{abstract}
This study provides further evidence with respect to findings reported by Stein et al. (1994) and O'Keefe et al. (1994) on the demand for the various grades of professional labor audit hours. These studies found that demand for audit hours was a function of three sets of client factors: size, complexity, and risk. However, contrary to what might be expected, they did not find that auditor learning had a significant effect. Using a data set consisting of 75 audits of publicly-held companies obtained from four international accounting firms, we test the generalizability of their findings to our more diverse data set and further examine the effects of auditor learning on audit hours. We find the results reported by Stein et al. and O'Keefe et al. generalizable to our data set, indicating their findings to be robust and our samples comparable. Although perhaps not of economic significance, the data also tends to suggest differential auditor learning across various staff levels in a complex relation. That is, the ability to observe learning is dependent on auditee size. There appears to be some learning for partners, managers, and seniors in audits of smaller auditees. However, given the limitations of our data set and consideration of economic significance versus statistical significance, the evidence is not convincingly strong in support of auditor learning on repeat engagements. We recommend further investigation as to whether both an auditor tenure indicator variable and a auditor tenure by auditee size interaction variable simultaneously considered in the model are an appropriate specification of the audit production function to capture auditor learning in a cross-sectional analysis.
\end{abstract}

Keywords: Audit production function, audit hours, auditor tenure, audit services.

\section{INTRODUCTION}

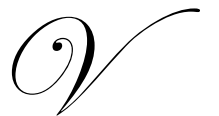

ery few studies have examined the effect of audit firm tenure on audit hours. The present study provides evidence beyond that of O'Keefe et al. (1994) and Stein et al. (1994) based upon a new sample different in terms of the number of audits, audit firms, and industries represented. Most studies considering auditor tenure involved audit fees rather than audit hours, and these studies provided mixed results. Because audit fee is a function of both audit hours and rate per hour, audit fees are not as fine a measure of audit efficiency as audit hours. Thus, there is a need to further investigate the relation of audit hours to auditor firm tenure rather than fees to tenure to get a firm grasp on whether learning occurs for new audits.

Stein et al. (1994) and O'Keefe et al. (1994) report that the demand for professional labor on audits depends on the client characteristics of size, complexity, and risk. They also report, contrary to expectations, that auditor firm learning, as measured by an auditor tenure indicator variable or an interaction variable of auditor tenure by auditee size in a cross-sectional analysis, is not related to the number of hours required to complete an audit. This finding is difficult to understand as auditors should benefit from learning which should result in a reduced number of hours needed for repeat audits of the same client.

\section{PRIOR RESEARCH}

There has been surprisingly little research that considered the effect of learning on audit hours. A review of some of the leading accounting and auditing journals ${ }^{1}$ identified only eight articles (other than O'Keefe et al. 1994 
and Stein et al. 1994) that considered auditor tenure in empirical studies, and all of these studies involved audit fees rather than audit hours. While audit hours and fees are related, factors such as low-balling, fixed-fee contracts, and competition reduce the correlation between audit hours and fees. The findings for audit fees may provide some indication of learning if audit firms expect that learning will affect the number of audit hours after the first year or first few years.

The results of these eight studies are mixed, with four (Barefield et al. 1993; Cullinan 1998; Behn et al. 1999; Craswell and Francis 1999) finding no significant effect and four (Simon and Francis 1988; Copley et al. 1994; Ward et al. 1994; Walker and Casterella 2000) finding some effect. Only two of eight studies (Simon and Francis; Walker and Casterella) find any evidence that audit firms may expect to be able to reduce audit hours due to learning. This lack of consistent findings may indicate either that there is very little auditor learning or that auditor learning occurs in a more complex manner than might be expected.

\section{RESEARCH QUESTION}

The expectation that there should be a learning curve in auditing (O'Keefe et al. 1994), combined with the mixed results of prior studies, indicate the necessity to examine auditor firm learning further. The regression models used by O'Keefe et al. (as discussed later) included a main effect term for auditor tenure or an interaction effect term for auditor tenure by assets, but not both concurrently. Since there appears to be no theoretical foundation for including either term alone or even both in the model to capture auditor learning, the inclusion of both terms may be required for proper model specification especially if the degree of learning observed is contingent upon auditee size. The question of whether one can observe decreased audit hours on repeat engagements as a function of auditee size, ceteris paribus, is addressed in the present study.

We expect that auditor learning, if it is observable, can be detected using both an indicator variable for auditor tenure and an interaction variable for auditee size by auditor tenure simultaneously; that is, auditor tenure may influence the curvature of the relation between client size and audit hours. A cross-section of audits is appropriate for detecting such learning curve.

O'Keefe et al. (1994) point out that "when audit technologies are constant, the best way to establish the existence and nature of learning curves in auditing would be through longitudinal analysis." (p. 252). Since it has been documented in the literature (Bamber et al. 1993; Gist 1994) that larger firms have been moving towards more structured audit methodologies, we cannot assume that audit technology is constant over time. A cross-sectional test for a period in time may be just as or even more powerful than a longitudinal test attempting to control for changing technology.

\section{METHOD}

Because of the number of factors that affect the audit production function, we follow the research approach used by Stein et al. (1994) and O'Keefe et al. (1994) to eliminate or control the effects of variables that are not of primary interest in this study. To minimize the effects of general environmental factors such as interest rates, growth or contraction of the economy, etc., Stein et al. and O'Keefe et al. restricted their sample to 1989 audits; we restricted our observations to the 1991 time period. In contrast to Stein et al. and O'Keefe et al., we restricted our sample to publicly-held companies to not have to consider potential systematic effects of privately-held and not-forprofit companies.

O'Keefe et al. (1994) minimized industry effects by considering data from three industries that were presumed to have similar asset structures: high technology, manufacturing, and merchandising. To provide evidence on the generality of the findings in O'Keefe et al. (1994), Stein et al. (1994) included 108 additional observations from financial services audit clients. In contrast to the approach taken in these studies, we do not restrict our sample by industry, except that in preliminary models we controlled for financial institutions and utilities (a total of seven observations). In these industries audit fees have been found to be systematically lower (Palmrose 1983, 1986; Simunic 1980). Industry indicator variables for financials and utilities were not significant in any of our models and 
therefore were omitted to avoid an overfitting problem. With the use of data from a variety of industries, our findings may be considered generalizable across industries. On the other hand, using a diverse data set may reduce the likelihood of finding significant results because of possible heteroscedasticity among the estimated regression coefficients. $^{2}$

A data-gathering form ${ }^{3}$ was drafted and revised after review by several partners and managers. Information was requested for the client and for the audit. Client information included industry ${ }^{4}$, number of consolidated subsidiaries, total number of reports issued, type of audit report, number of locations audited, number of times the client was audited by the firm, existence of internal auditors and audit committees, and financial information on assets, liabilities, and income. Audit information included the reported number of audit hours by each staff level (partner, manager, senior, and junior).

TABLE 1

DESCRIPTIVE DATA

Client statistics

$(\mathbf{n}=\mathbf{7 5})$

\begin{tabular}{|c|c|c|c|c|}
\hline & & STD. & & \\
\hline & MEAN & $\overline{\mathrm{DEV}}$. & MEDIAN & RANGE \\
\hline Total reported audit hours & 836 & 680 & 556 & 33 to 3110 \\
\hline Total partner hours & 37 & 33 & 27 & 0 to 157 \\
\hline Total manager hours & 104 & 79 & 74 & 0 to 400 \\
\hline Total senior hours & 267 & 201 & 200 & 0 to 1200 \\
\hline Total junior hours & 386 & 362 & 250 & 0 to 1650 \\
\hline ASSET (in thousands) & $\$ 263,000$ & $\$ 625,000$ & $\$ 68,000$ & $\$ 300$ to $3,674,000$ \\
\hline FRGN & .03 & .13 & 0 & 0 to $80 \%$ \\
\hline REPORTS & 1.80 & 2.19 & 1 & 1 to 10 \\
\hline SUB & 2.69 & 3.88 & 1 & 0 to 16 \\
\hline LOC & 2.07 & 2.51 & 1 & 1 to 15 \\
\hline LEVERAGE & .37 & .38 & .26 & 0 to .75 \\
\hline DEFREC & .24 & .21 & .19 & 0 to .85 \\
\hline DEFINV & .16 & .18 & .11 & 0 to .65 \\
\hline ROA & .04 & .18 & .03 & -.60 to 1.18 \\
\hline PROFIT MARGIN & .06 & .24 & .03 & -.67 to 1.60 \\
\hline
\end{tabular}

Percentage of auditees with:

Internal Audit Department (INTERNAL AUD) 31

Audit Tenure of 1 Year or less (AUDT1) 12

$\begin{array}{lr}\text { Audit Tenure of } 2 \text { Years (AUDT2) } & 12\end{array}$

Audit Tenure of 3 Years (AUDT3) 13

Where:

ASSET

FRGN

REPORTS

SUB

LOC

LEVERAGE

DEFREC

DEFINV

ROA

Audit Tenure of 4 Years or more

PROFIT MARGIN

$=$ Total assets at year end

$=$ Foreign assets/assets

$=$ Number of audit reports prepared

$=$ Number of consolidated subsidiaries

$=$ Number of audit locations

$=$ Total liabilities/Total assets

$=$ Total receivables/assets

$=$ Total inventory/assets

$=$ Net income $($ loss $) /$ assets

$=$ Net income $($ loss $) /$ Revenue

INTERNAL AUD

$=$ Indicator variable $(0,1)$ where " 1 " if client has internal auditors

$=$ Indicator variable $(0,1)$ where " 1 " if a first audit of this client by auditor

$=$ Indicator variable $(0,1)$ where " 1 " if a second audit of this client by auditor

AUDT2

AUDT3

$=$ Indicator variable $(0,1)$ where " 1 " if a third audit of this client by auditor 
Offices of international accounting firms were contacted to solicit their participation in this study by providing detailed confidential information on a random sample of 25 of their publicly-held clients. We attempted to minimize response bias by requiring a random sample ${ }^{5}$ and restricting our data gathering from only international firms. Use of only international auditors also provides for control over audit quality. We received 88 data sets from four accounting firms. Not all of the forms were usable, mainly because they were incomplete or not related to publicly-traded companies. The final usable sample consisted of 75 audits; descriptive statistics for these audits are shown in Table 1.

The size of audit clients in the sample varies widely with assets ranging from $\$ .3$ million to $\$ 3,674$ million (with a mean of $\$ 263$ million) 6 . Thirty-one percent of our sample has internal auditors and 63 percent of external auditors has tenure of four or more years. For both the financial and industrial institution subsamples of Stein et al., 71.2 percent of external auditors has tenure of four or more years; for 27.8 percent of their financial institutions internal audit assistance was extensive, whereas for only 6.4 percent of their industrial institutions was internal audit assistance extensive.

\section{RESEARCH DESIGN}

Since production theory does not suggest a specific functional form of the relation between audit hours and its determinants, we examine three different functional forms of the empirical model considered by O'Keefe et al. (1994) as O'Keefe et al. found their results to be robust to the choice of functional form. Because of the constant variance assumption, prior researchers found it necessary to linearize the relation between audit fees (or audit hours) and client assets to correct for heteroscedasticity. Prior research has also shown client size alone explains more than $50 \%$ of the variation in audit fees, although other client factors influence both fees and hours.

The first functional form of the model recognizes the importance of client size in determining audit hours. The natural logarithm of both hours and total assets is used to linearize the relation. The model assumes that the effect of other client characteristics on audit hours is dependent on the level of client assets. In the empirical model this would be shown as interaction variables of other characteristics and the log of assets. The empirical model is as follows:

$\mathrm{k}$

$$
\operatorname{Ln} h_{j}=B_{j 0}+B_{j 1} \ln A+B_{j 2} X \ln A+\sum_{i=3} B_{j i} Y_{i} \ln A
$$

(Model 1)

where, $\mathrm{h}$ denotes audit hours, $\mathrm{A}$ denotes client size in terms of assets, $\mathrm{X}$ is an auditor tenure classification variable, and $Y_{i}$ depicts all other client characteristics of complexity, risk, and the audit firm indicator variable. Note that the use of data collected from only one audit firm by Stein et al. (1994) and O'Keefe et al. (1994) results in their holding the audit firm constant.

Another empirical model considered by O'Keefe et al. (1994) and tested on the data of the present study assumes all client characteristics to be equally important. This model was also used by Ashton et al. (1987). In this model the main effect term for auditor tenure is included, but the auditor tenure by $\log$ of assets interaction term is omitted. In addition to using the $\log$ of audit hours and client size, other client characteristics measured in continuous form are also transformed using the natural logarithm. The linear model is stated as:

$\mathrm{k}$

$$
\operatorname{Ln} h_{j}=B_{j 0}+B_{j 1} X+B_{j 2} \ln A+\sum_{i=3} B_{j i} \ln Y_{i}
$$

(Model 2)

By using the models specified in O'Keefe et al. (1994) and Stein et al. (1994), we are able to determine whether our results using a different sample are consistent with the results of those studies. 


\section{Model Specified For The Present Study}

We ran another empirical model, specified based on the sampling distribution of variables, which is a slight variation of the second and third empirical models tested by O'Keefe et al. We started out by taking the log of only audit hours and total assets because of the non-linear relation between these two variables. Also, based on prior research, these are the variables usually transformed to correct for nonconstant variance in the residuals. It was then considered necessary to use the log transformation for four other variables controlling for complexity (i.e., number of consolidated subsidiaries, number of audit locations, and number of reports prepared) and risk (i.e., return on assets) because of skewness in these variables as indicated by the magnitude of the relation between the mean and median.

Skewness can cause model residuals not to be normally distributed although this did not appear to be a problem with the O'Keefe et al. study, possibly due to their much larger sample size relative to ours. O'Keefe et al. either transformed all other variables controlling for complexity and risk (i.e., their second empirical model) or utilized the untransformed measurement of these variables (i.e., their third empirical model) in the functional formulation of their model. Variable skewness was a necessary consideration in our model formulation. According to Hair et al. (1995, pgs. 76-77), data transformations provide the principal means of correcting nonnormality and heteroscedasticity; skewed distributions can be transformed by taking the logarithms of the variables.

The first reduced form of our empirical model without the auditor tenure by assets interaction term is:

$$
\begin{aligned}
\operatorname{Ln} h_{j}= & B_{j 0}+B_{j 1} X+B_{j 2} \ln A+B_{j 3} \ln S+B_{j 4} \ln L+B_{j 5} \ln R+B_{j 6} \ln R O A \\
& +\sum_{i=7}^{k} B_{j i} Y_{i}
\end{aligned}
$$

where, $\mathrm{h}=$ audit hours, $\mathrm{X}=$ auditor tenure classification variable, $\mathrm{A}=$ total assets, $\mathrm{S}=$ number of subsidiaries, $\mathrm{L}=$ number of audit locations, $\mathrm{R}=$ number of reports prepared, $\mathrm{ROA}=$ return on assets, and $\mathrm{Y}_{\mathrm{i}}=$ all other client characteristics measuring complexity, risk, and audit firm indicator. The above model is derived from the following underlying functional relation:

$h_{j}=e^{B_{j 0}+B_{j 1} X+\sum_{i=7}^{k} B_{j i} Y_{i}} \quad B_{j 2} S^{B_{j 3}} \quad B^{B_{j 4}} R^{B_{j 5}} R O A{ }^{B_{j 6}}$

(Model 3a)

A second reduced model (not shown) excludes the auditor tenure main effect term $(\mathrm{X})$ and includes a auditor tenure by assets interaction term $(\mathrm{X} * \mathrm{Ln} \mathrm{A})$. The full model (not shown) includes both auditor tenure main effect and interaction terms.

Since this paper focuses on whether the influence of auditor tenure is contingent upon auditee size, and there appears to be no theoretical foundation for whether to consider either an auditor tenure main effect term or its interaction with client size or both simultaneously in the audit effort model, Model 3 was run (as displayed with just the auditor tenure main effect variables - Table 2). Next, the model was rerun omitting the auditor tenure main effect variables but including the interaction variables (Table 3). Then the full model was run including both auditor tenure main effect and interaction variables (Table 4). Coefficients of the test variables and explanatory power of each model are examined for significance and changes.

Given the lack of accounting theory, our preference is for the full model (in which the interaction term is a function of variables already entered into the model), unless multicollinearity is problematic. Support for this model specification is provided in a discussion of interaction or moderating effects in the statistical text by Hair et al. (1995, pgs. 170-171); they express the necessity to observe the change in $\mathrm{R}^{2}$ in assessing a significant moderating effect in this model formulation. Collinearity diagnostics are calculated to address the issue of multicollinearity. 
For each of our models, five regression equations were run using total actual audit hours, partner hours, manager hours, senior hours, and junior hours as dependent variables individually. In addition to functional form, the variables or proxies employed in these models are similar to those used by O'Keefe et al. (1994) and Stein et al. (1994) with respect to controlling or measuring the general factors of size, complexity, and risk, except that we do not consider the variables they found not to make a contribution. We do not include the variable that measured the degree of reliance on client's internal controls as this variable was not significant in any of Stein et al.'s five full models. We also do not consider the degree of auditor involvement in management consulting or tax services as Stein et al. found these variables had no significant effect. The next section discusses the results and is followed by a section on tests of alternative model specifications, then the summary and conclusion.

\section{RESULTS}

When using our data set to run the three empirical models tested by O'Keefe et al. and Stein et al. (results not displayed), we find substantially similar results of no evidence of auditor learning. Being able to replicate their results with very high explanatory power (ranging from 58\% to $78 \%$ ) and significant size, complexity, risk and auditor identification variables, suggest comparability between our sample and those of O'Keefe et al. and Stein et al. ${ }^{8}$ Neither auditor tenure main effect nor auditor tenure interaction effect was significant; and the coefficients and significance level of all other client factors did not change when considering both slope change (interaction effect) and intercept shift (auditor tenure effect) simultaneously in their models. The latter suggests that any collinearity induced by this model formulation did not cause instability of parameters.

\section{Results Of Model Specified For Present Study}

Results of the first reduced model specified for the current study (Model 3), considering only the auditor tenure main effect variables, are shown in Table 2. The coefficients of the auditor tenure main effect variables (in a parsimonious model) are expected to be positive (indicating that the first three audits are relatively inefficient compared to later audits), and in the following order as learning should occur immediately after the first audit: AUDT1> AUDT2> AUDT3. The effect of auditor tenure for four or more years is embedded in the intercept. As Table 2 indicates, when the auditor tenure interaction variables are not considered none of the 15 main effect variables is significant and seven are negative in this restricted model. There are significant size, risk, and complexity variables in the expected direction, and significant firm indicator variables. Because of concern for overfitting the models, we dropped the firm indicator variables as all firms are international with similar audit methodology, and the literature assumes similar audit quality among the international as compared to the noninternational firms. Results are substantially the same with and without firm indicator variables. Adjusted $\mathrm{R}^{2}$ 's of the models range from .60 to .80 .

We then ran the second reduced model specified for the current study, which considers only the auditor tenure variables interacting with assets. As Table 3 shows, when the auditor tenure main effect variables are excluded, none of the 15 interaction variables is significant and ten are negative in this restricted model. There are significant size, risk, and complexity variables in the expected direction. The adjusted $\mathrm{R}^{2}$ s $\mathrm{s}$ of the models range from .60 to .80 . 
TABLE 2

Regression of Aggregate and Disaggregated Labor Hours on Client Characteristics Reduced Model with Auditor Tenure Main Effect

$(\mathbf{n}=\mathbf{7 5})$

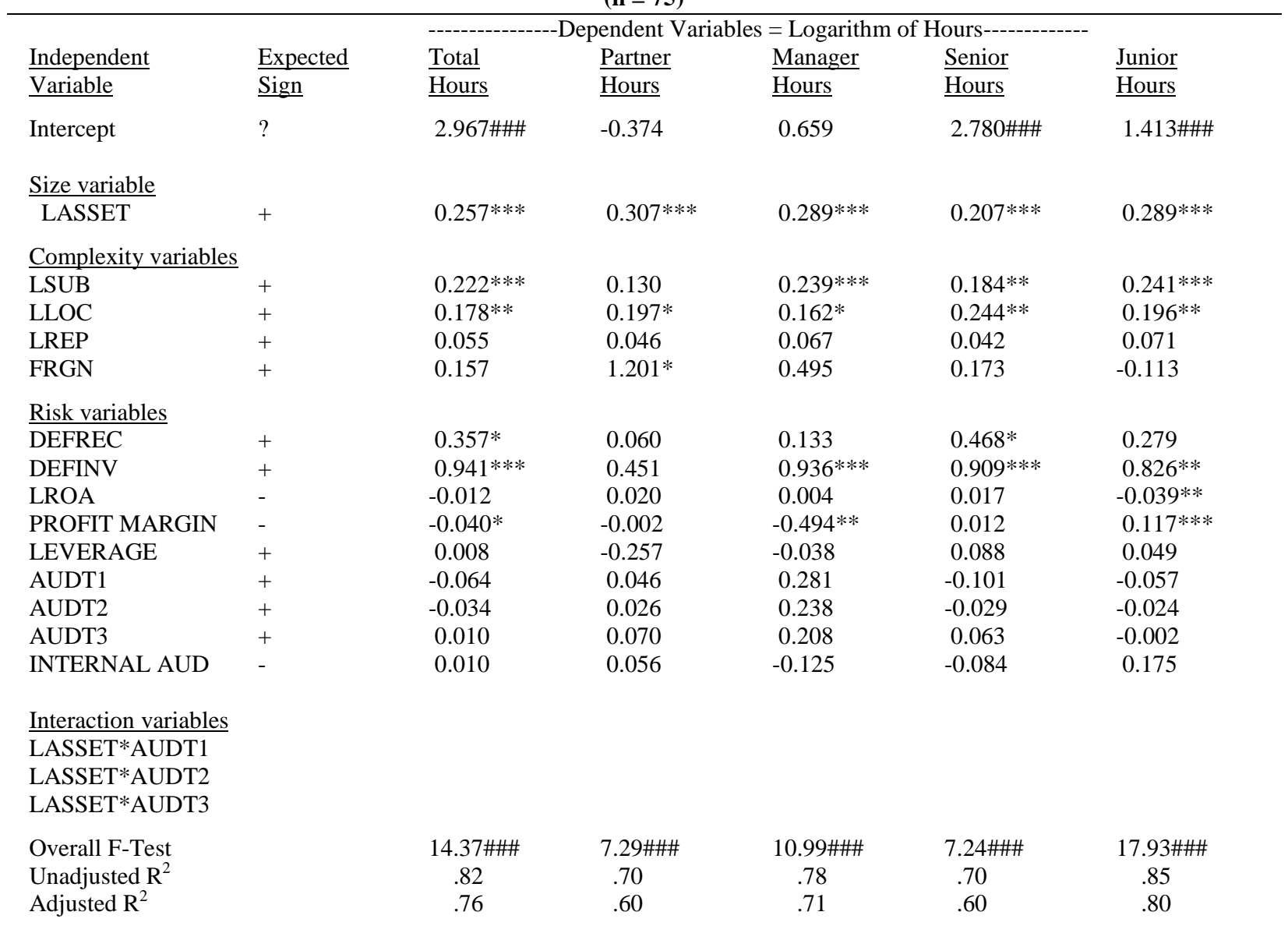

Significant at .10: * (one-tailed); \# (two-tailed)

Significant at .05: ** (one-tailed); \#\# (two-tailed)

Significant at .01: *** (one-tailed); \#\#\# (two-tailed)

Where:

LASSET
LSUB
LLOC
LREP
FRGN
DEFREC
DEFINV
LROA
PROFIT MARGIN
LEVERAGE
AUDT1
AUDT2
AUDT3
INTERNAL AUD
FIRM1
FIRM2
FIRM3

$=$ Natural logarithm of Total assets (in thousands) at year end

$=$ Natural logarithm of number of consolidated subsidiaries

$=$ Natural logarithm of number of audit locations

$=$ Natural logarithm of number of audit reports

$=$ Total foreign assets/Total assets at year end

$=$ Total receivables/Total assets

$=$ Total inventory/Total assets

$=$ Natural logarithm of Net income (loss)/Total assets

$=$ Net income $($ loss $) /$ Revenue

$=$ Total liabilities/Total assets

$=(0,1)$ indicator variable, where " 1 " if a first audit of this client by the auditor

$=(0,1)$ indicator variable, where " 1 " if a second audit of this client by the auditor

$=(0,1)$ indicator variable, where " 1 " if a third audit of this client by the auditor

$=(0,1)$ indicator variable, where " 1 " if client has internal audit department

$=$ Indicator variable for identity of audit firm 1

$=$ Indicator variable for identity of audit firm 2

$=$ Indicator variable for identity of audit firm 3 
TABLE 3

Regression of Aggregate and Disaggregated Labor Hours on Client Characteristics Reduced Model with Auditor Tenure Interaction Effect $(\mathbf{n}=\mathbf{7 5})$

\begin{tabular}{|c|c|c|c|c|c|c|}
\hline \multirow{3}{*}{$\begin{array}{l}\text { Independent } \\
\text { Variable }\end{array}$} & \multirow[b]{2}{*}{ Expected } & \multicolumn{4}{|c|}{ - } & \multirow[b]{2}{*}{$\underline{\text { Junior }}$} \\
\hline & & $\underline{\text { Total }}$ & $\underline{\text { Partner }}$ & Manager & $\underline{\text { Senior }}$ & \\
\hline & $\underline{\text { Sign }}$ & $\underline{\text { Hours }}$ & $\underline{\text { Hours }}$ & $\underline{\text { Hours }}$ & $\underline{\text { Hours }}$ & $\underline{\text { Hours }}$ \\
\hline Intercept & $?$ & 2.944\#\#\# & -0.354 & $0.802 \# \#$ & 2.671\#\#\# & 1.393\#\#\# \\
\hline \multicolumn{7}{|l|}{$\underline{\text { Size variable }}$} \\
\hline LASSET & + & $0.261 * * *$ & $0.307 * * *$ & $0.278 * * *$ & $0.211 * * *$ & $0.293 * * *$ \\
\hline \multicolumn{7}{|l|}{ Complexity variables } \\
\hline LSUB & + & $0.222 * * *$ & 0.129 & $0.237 * * *$ & $0.182 * *$ & $0.243 * * *$ \\
\hline LLOC & + & $0.168 * *$ & $0.193^{*}$ & $0.162 *$ & $0.234 * *$ & $0.181 *$ \\
\hline LREP & + & 0.055 & 0.044 & 0.058 & 0.040 & 0.073 \\
\hline FRGN & + & 0.101 & $1.150^{*}$ & 0.450 & 0.106 & -0.173 \\
\hline \multicolumn{7}{|l|}{$\underline{\text { Risk variables }}$} \\
\hline DEFREC & + & $0.368 *$ & 0.070 & 0.110 & $0.488 *$ & 0.273 \\
\hline DEFINV & + & $0.938 * * *$ & 0.440 & $0.925 * * *$ & $0.903 * * *$ & $0.830 * *$ \\
\hline LROA & - & -0.012 & 0.020 & 0.006 & 0.017 & $-0.040 * *$ \\
\hline PROFIT MARGIN & - & $-0.038^{*}$ & -0.003 & $-0.502 * *$ & 0.010 & $0.115 * * *$ \\
\hline LEVERAGE & + & 0.026 & -0.243 & -0.023 & 0.110 & 0.068 \\
\hline \multicolumn{7}{|l|}{ AUDT1 } \\
\hline \multicolumn{7}{|l|}{ AUDT2 } \\
\hline \multicolumn{7}{|l|}{ AUDT3 } \\
\hline INTERNAL AUD & - & 0.011 & 0.056 & -0.110 & -0.086 & 0.181 \\
\hline \multicolumn{7}{|l|}{ Interaction variables } \\
\hline $\begin{array}{l}\text { LASSET*AUDT1 } \\
*\end{array}$ & + & -0.009 & -0.0002 & 0.024 & -0.014 & -0.005 \\
\hline LASSET*AUDT2 & + & -0.011 & -0.003 & 0.019 & -0.012 & -0.011 \\
\hline LASSET*AUDT3 & + & -0.001 & 0.005 & 0.016 & 0.005 & -0.005 \\
\hline Overall F-Test & & $14.55 \# \# \#$ & 7.29\#\#\# & 10.79\#\#\# & 7.38\#\#\# & 18.07\#\#\# \\
\hline Unadjusted $\mathrm{R}^{2}$ & & .82 & .70 & .78 & .70 & .85 \\
\hline Adjusted $\mathrm{R}^{2}$ & & .76 & .60 & .70 & .60 & .80 \\
\hline
\end{tabular}

Significant at .10: * (one-tailed); \# (two-tailed)

Significant at .05: ** (one-tailed); \#\# (two-tailed)

Significant at .01: *** (one-tailed); \#\#\# (two-tailed)

Where:

\begin{tabular}{|c|c|c|}
\hline LASSET & $=$ & Natural logarithm of Total assets (in thousands) at year end \\
\hline LSUB & $=$ & Natural logarithm of number of consolidated subsidiaries \\
\hline LLOC & $=$ & Natural logarithm of number of audit locations \\
\hline LREP & $=$ & Natural logarithm of number of audit reports \\
\hline FRGN & $=$ & Total foreign assets/Total assets at year end \\
\hline DEFREC & $=$ & Total receivables/Total assets \\
\hline DEFINV & $=$ & Total inventory/Total assets \\
\hline LROA & $=$ & Natural logarithm of Net income (loss)/Total assets \\
\hline PROFIT MARGIN & $=$ & Net income (loss)/Revenue \\
\hline LEVERAGE & $=$ & Total liabilities/Total assets \\
\hline AUDT1 & $=$ & $(0,1)$ indicator variable, where " 1 " if a first audit of this client by the auditor \\
\hline AUDT2 & $=$ & $(0,1)$ indicator variable, where " 1 " if a second audit of this client by the auditor \\
\hline AUDT3 & $=$ & $(0,1)$ indicator variable, where " 1 " if a third audit of this client by the auditor \\
\hline INTERNAL AUD & $=$ & $(0,1)$ indicator variable, where " 1 " if client has internal audit department \\
\hline FIRM1 & $=$ & Indicator variable for identity of audit firm 1 \\
\hline FIRM2 & $=$ & Indicator variable for identity of audit firm 2 \\
\hline FIRM3 & $=$ & Indicator variable for identity of audit firm 3 \\
\hline
\end{tabular}


TABLE 4

Regression of Aggregate and Disaggregated Labor Hours on Client Characteristics Full (Parsimonious) Model

$(\mathbf{n}=\mathbf{7 5})$

\begin{tabular}{|c|c|c|c|c|c|c|}
\hline \multirow[b]{2}{*}{ Independent } & \multicolumn{6}{|c|}{ 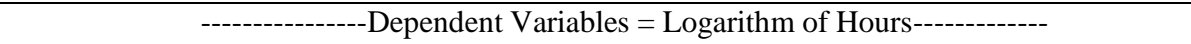 } \\
\hline & Expected & $\underline{\text { Total }}$ & $\underline{\text { Partner }}$ & Manager & $\underline{\text { Senior }}$ & Junior \\
\hline Variable & $\underline{\text { Sign }}$ & $\underline{\text { Hours }}$ & $\overline{\text { Hours }}$ & $\underline{\text { Hours }}$ & $\overline{\text { Hours }}$ & $\overline{\text { Hours }}$ \\
\hline Intercept & $?$ & $2.072 \# \# \#$ & $-1.129 \#$ & 0.206 & 1.749\#\#\# & 0.461 \\
\hline \multicolumn{7}{|l|}{$\underline{\text { Size variable }}$} \\
\hline LASSET & + & $0.333 * * *$ & $0.373 * * *$ & $0.327 * * *$ & $0.297 * * *$ & $0.367 * * *$ \\
\hline \multicolumn{7}{|l|}{$\underline{\text { Complexity variables }}$} \\
\hline LSUB & + & $0.230 * * *$ & 0.126 & $0.247 * * *$ & $0.178 * * *$ & $0.274 * * *$ \\
\hline LLOC & + & $0.167 * *$ & $0.204 *$ & $0.176 *$ & $0.239 * *$ & $0.169 *$ \\
\hline LREP & + & 0.103 & 0.077 & 0.092 & 0.085 & $0.140^{*}$ \\
\hline FRGN & + & 0.266 & $1.276^{*}$ & 0.528 & 0.283 & 0.028 \\
\hline \multicolumn{7}{|l|}{ Risk variables } \\
\hline DEFREC & + & $0.571 * *$ & 0.235 & 0.216 & $0.716 * * *$ & $0.503^{*}$ \\
\hline DEFINV & + & $0.980 *$ & 0.527 & $0.962 * * *$ & $1.008 * * *$ & $0.786 * *$ \\
\hline LROA & - & -0.020 & 0.013 & -0.001 & 0.007 & $-0.046 * *$ \\
\hline PROFIT MARGIN & - & $0.036 *$ & -0.006 & $-0.432 *$ & 0.007 & $0.116^{* * * *}$ \\
\hline LEVERAGE & + & -0.056 & -0.312 & -0.076 & 0.011 & -0.016 \\
\hline AUDT1 & + & 1.398 & $2.452 *$ & $1.927 *$ & $2.370 * *$ & 0.222 \\
\hline AUDT2 & + & $1.799 * * *$ & $1.416 *$ & 0.827 & $2.092 * * *$ & $1.933 * * *$ \\
\hline AUDT3 & + & 0.864 & 0.499 & 0.895 & 0.495 & $1.716 * *$ \\
\hline INTERNAL AUD & - & -0.095 & -0.048 & -0.191 & $-0.220 *$ & 0.087 \\
\hline \multicolumn{7}{|l|}{ Interaction variables } \\
\hline LASSET*AUDT1 & + & -0.144 & $-0.241 *$ & -0.166 & $-0.246 * *$ & -0.022 \\
\hline LASSET*AUDT2 & + & $-0.167 * * *$ & $-0.126 *$ & -0.054 & $-0.193 * * *$ & $-0.178 * * *$ \\
\hline LASSET*AUDT3 & + & -0.076 & -0.038 & -0.061 & -0.038 & $-0.153 * *$ \\
\hline Overall F-Test & & 13.51\#\#\# & 6.32\#\#\# & $9.16 \# \# \#$ & 7.27\#\#\# & 16.67\#\#\# \\
\hline Unadjusted $\mathrm{R}^{2}$ & & .84 & .71 & .79 & .74 & .87 \\
\hline Adjusted $\mathrm{R}^{2}$ & & .78 & .60 & .70 & .64 & .82 \\
\hline
\end{tabular}

Significant at .10: * (one-tailed); \# (two-tailed)

Significant at .05: ** (one-tailed); \#\# (two-tailed)

Significant at .01: *** (one-tailed); \#\#\# (two-tailed)

Where:

\begin{tabular}{|c|c|c|}
\hline LASSET & $=$ & Natural logarithm of Total assets (in thousands) at year end \\
\hline LSUB & $=$ & Natural logarithm of number of consolidated subsidiaries \\
\hline LLOC & $=$ & Natural logarithm of number of audit locations \\
\hline LREP & $=$ & Natural logarithm of number of audit reports \\
\hline FRGN & $=$ & Total foreign assets/Total assets at year end \\
\hline DEFREC & $=$ & Total receivables/Total assets \\
\hline DEFINV & $=$ & Total inventory/Total assets \\
\hline LROA & $=$ & Natural logarithm of Net income (loss)/Total assets \\
\hline PROFIT MARGIN & $=$ & Net income (loss)/Revenue \\
\hline LEVERAGE & $=$ & Total liabilities/Total assets \\
\hline AUDT1 & $=$ & $(0,1)$ indicator variable, where " 1 " if a first audit of this client by the auditor \\
\hline AUDT2 & $=$ & $(0,1)$ indicator variable, where " 1 " if a second audit of this client by the auditor \\
\hline AUDT3 & $=$ & $(0,1)$ indicator variable, where " 1 " if a third audit of this client by the auditor \\
\hline INTERNAL AUD & $=$ & $(0,1)$ indicator variable, where " 1 " if client has internal audit department \\
\hline FIRM1 & $=$ & Indicator variable for identity of audit firm 1 \\
\hline FIRM2 & $=$ & Indicator variable for identity of audit firm 2 \\
\hline FIRM3 & $=$ & Indicator variable for identity of audit firm 3 \\
\hline
\end{tabular}


Next, the full (parsimonious) model, with both main effect and interaction effect variables, was run. For this unrestricted model, as shown in Table 4 the auditor tenure main effect variables are in the expected direction and significant for certain staff levels. The 15 main effect variables are all positive and eight are significant at the .10 level or less. All 15 interaction variables are negative, with seven significant. The models are significant with adjusted $\mathrm{R}^{2}$ s ranging from .60 to .82 . Thus, it appears that both main effect and interaction effect terms are needed for proper specification of the model since neither term entered alone is significant. ${ }^{9,}{ }^{10}$ Further, as discussed below, the interaction between auditor tenure and auditee size is much more complex (as evidenced by the negative coefficient) than could have been anticipated a priori.

At this stage of analyses, the regression models in Table 4 tend to suggest that auditor learning does occur, but the extent to which it can be observed is dependent upon auditee size. The first year audit variables for partners, managers, and seniors are significant, indicating that most learning occurs during the first audit. The reducing magnitude of the main effect coefficients indicates that as auditor tenure increases, audit hours are decreasing.

The coefficients of the interaction variables are negative and decreasing in magnitude (except for juniors) as auditor tenure increases; that is, the slope of the regression line is increasing as auditor tenure increases. Stated differently, increasing auditor tenure results in a smaller reduction in audit hours for larger auditees compared to that for smaller auditees. This suggests that additional hours required for larger and more complex operations offset savings in hours due to learning. The effects are more complex than was expected $a$ priori, and hence, the negative coefficient on the interaction variables is contrary to initial expectations. In addition, the differences in magnitude of coefficients of auditor tenure variables across the different grades of labor suggest that the effects of auditor learning are not realized consistently.

The above results are tentative and must be interpreted with caution especially since statistical significance may not equate to economic significance. The largest increase in model $\mathrm{R}^{2}$ is from .60 to .64 for seniors. For juniors and total audit hours, the increase in explanatory power of the full models over the reduced models is only two percent. Further, a curious finding is observed when comparing the full model to the model omitting both main effect and interaction effect terms for auditor tenure: for all staff levels, the full model does not provide any incremental explanatory power over the model excluding both auditor tenure variables. This suggests that when auditor tenure is examined, that because of its interrelation with client size, both main effect and interaction effect must be considered for proper specification. This interpretation is based in part on auditor tenure variables being found to be significant only in the full model, in spite of the lack of a substantial increase in $\mathrm{R}^{2}$. Taken as a whole, these results tend to imply that if learning does occur on repeat audit engagements, it is not of economic significance.

\section{Analysis Of Response Functions}

To further investigate the relation between tenure and client size, we examine response functions. Because both intercepts and slopes differ for various classes when interaction effects are present, the effect of the qualitative variable can be studied only by comparing the regression functions for each class of the qualitative variable (Neter et al. 1983, 336). In other words, when significant interactions exist, the coefficient of the class variable no longer indicates how much higher (lower) one response line is than the other (i.e., how much higher or lower audit hours for different levels of auditor tenure). One must consider the total response function. We examine the different response functions for the different levels of the auditor tenure variable by substituting indicator variables and reducing the audit hours equation for each staff level. We begin with senior audit hours as learning is very pronounced for seniors.

The senior audit hours equation of Table 4 is rewritten as follows:

$$
\begin{array}{ll}
\text { LSENHRS } & =\mathrm{C}+1.749+0.297 \mathrm{LASSET}+2.370 \text { AUDT } 1+2.092 \text { AUDT2 +0.495AUDT3 }- \\
& \text { 0.246LASSET*AUDT } 1-0.193 \text { LASSET*AUDT2 }-0.038 \text { LASSET*AUDT3 }
\end{array}
$$

where: 
LSENHRS = Natural log of senior audit hours,

C $\quad=$ Sum of all factors in the model (i.e., the product of the respective coefficients and the means of the variables), except the intercept, auditee size variable, auditor tenure variables, and auditor tenure by auditee size interaction variables.

Response function for auditor tenure $>3$ years, for which AUDT1 $=0$, AUDT2 $=0$, and AUDT3 $=0$ :

LSENHRS $\quad=\mathrm{C}+1.749+0.297$ LASSET

Response function for auditor tenure of 1 year, for which AUDT2 $=0$ and AUDT3 $=0$ :

LSENHRS $\quad=\mathrm{C}+1.749+0.297$ LASSET +2.370 AUDT $1-0.246$ LASSET $*$ AUDT 1

$=\mathrm{C}+4.119+.051$ LASSET

Response function for auditor tenure of 2 years, for which AUDT1 $=0$ and AUDT3 $=0$ :

LSENHRS $\quad=\mathrm{C}+1.749+0.297$ LASSET +2.092 AUDT2 -0.193 LASSET $*$ AUDT2

$=\mathrm{C}+3.841+.104$ LASSET

Response function for auditor tenure of 3 years, for which AUDT1 $=0$ and AUDT2 $=0$ :

LSENHRS $\quad=\mathrm{C}+1.749+0.297$ LASSET +0.495 AUDT3 -0.038 LASSET $*$ AUDT3

$=\mathrm{C}+2.244+.259$ LASSET

The total audit hours equation of Table 4 is rewritten as follows:

LTOTHRS $=\mathrm{C}+2.072+0.333$ LASSET +1.398 AUDT $1+1.799$ AUDT2 +0.864 AUDT3 0.144LASSET*AUDT1 - 0.167LASSET*AUDT2 - 0.076LASSET*AUDT3

where:

LTOTHRS = Natural log of total audit hours,

C $=$ Sum of all factors in the model (i.e., the product of the respective coefficients and the means of the variables), except the intercept, auditee size variable, auditor tenure variables, and auditor tenure by auditee size interaction variables.

Response function for auditor tenure $>3$ years, for which AUDT1 $=0$, AUDT2 $=0$, and AUDT3 $=0$ :

LTOTHRS $\quad=\mathrm{C}+2.072+0.333$ LASSET

Response function for auditor tenure of 1 year, for which AUDT2 $=0$ and AUDT3 $=0$ :

LTOTHRS $=\mathrm{C}+2.072+0.333$ LASSET +1.398 AUDT $1-0.144$ LASSET $*$ AUDT 1

$=\mathrm{C}+3.470+.189$ LASSET

Response function for auditor tenure of 2 years, for which AUDT1 $=0$ and AUDT3 $=0$ :

LTOTHRS $=\mathrm{C}+2.072+0.333$ LASSET +1.799 AUDT2 -0.167 LASSET $*$ AUDT2

$=\mathrm{C}+3.871+.166 \mathrm{LASSET}$

Response function for auditor tenure of 3 years, for which AUDT1 $=0$ and AUDT2 $=0$ :

LTOTHRS $=\mathrm{C}+2.072+0.333$ LASSET +0.864 AUDT $3-0.076$ LASSET $*$ AUDT 3

$=\mathrm{C}+2.936+.257 \mathrm{LASSET}$ 


\section{Figure 1}

Plot of Total Audit Hours (Log) Response Function for

Auditor Tenure by Auditee Size Interaction Effect

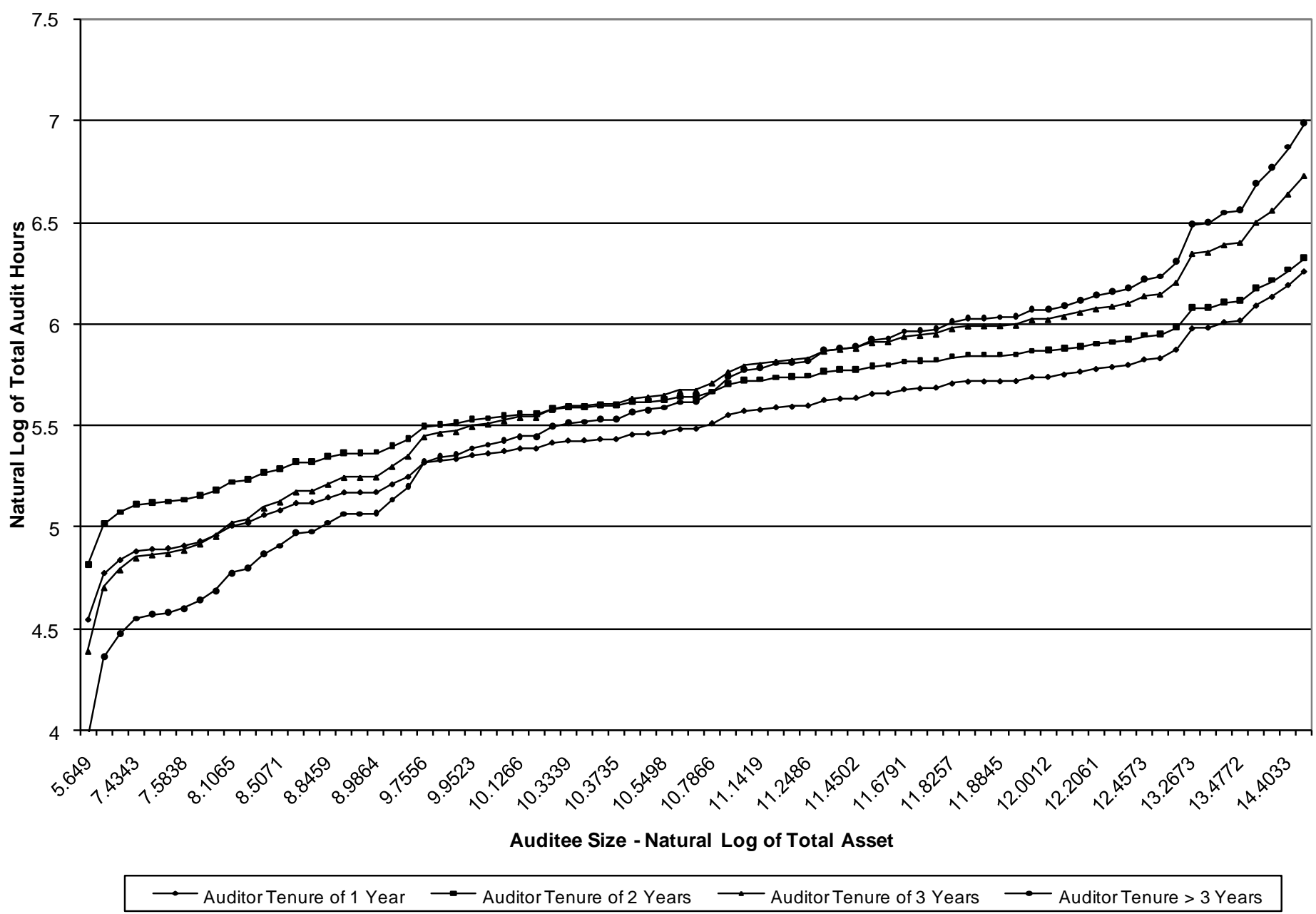


Figure 2

Plot of Partner Audit Hours (Log) Response Function for Auditor Tenure by Auditee Size Interaction Effect

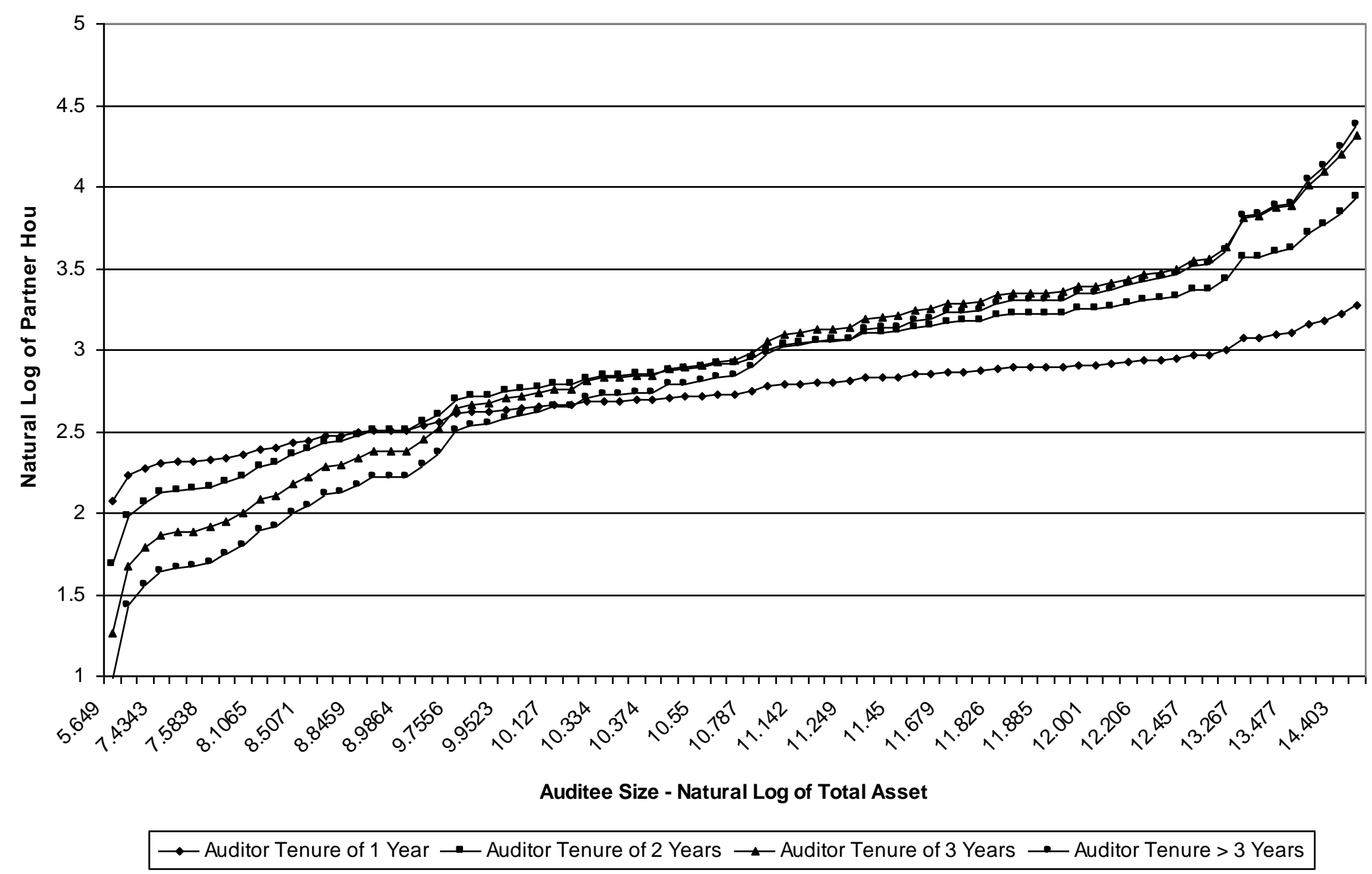


Figure 3

Plot of Manager Audit Hours (Log) Response Function for Auditor Tenure by Auditee Size Interaction Effect

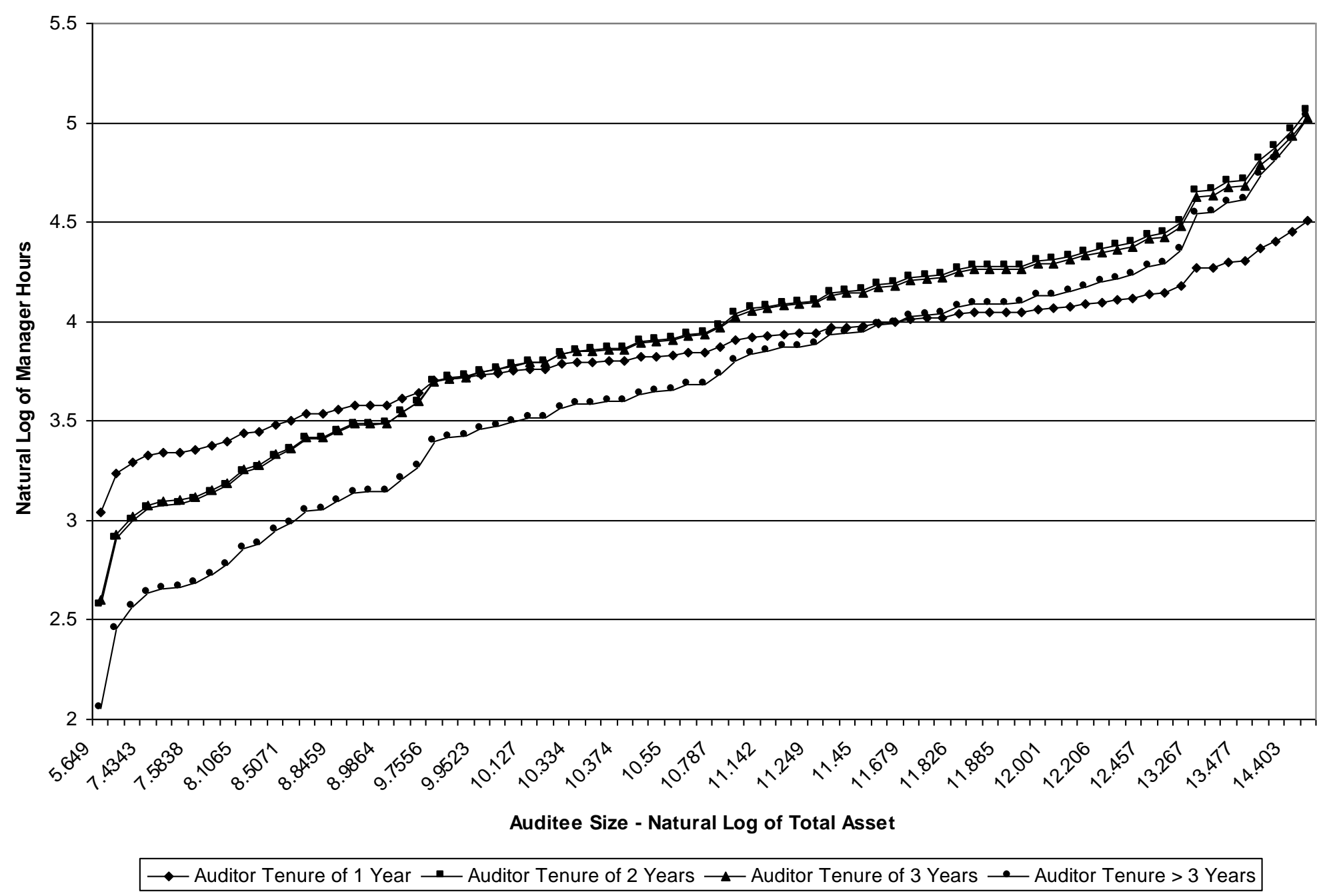


Figure 4

Plot of Senior Audit Hours (Log) Response Function for Auditor Tenure by Auditee Size Interaction Effect

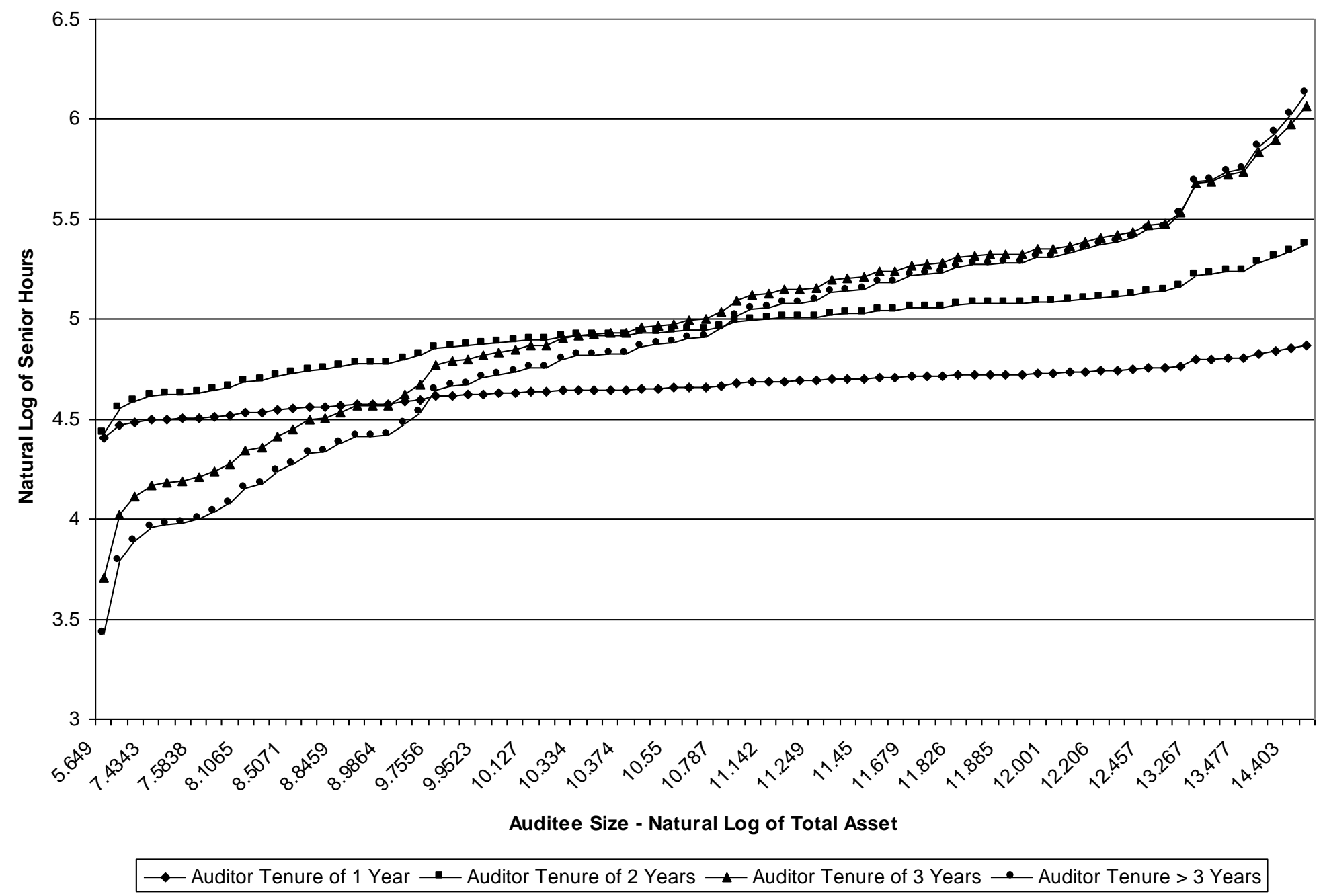


Figure 5

Plot of Junior Audit Hours (Log) Response Function for Auditor Tenure by Auditee Size Interaction Effect

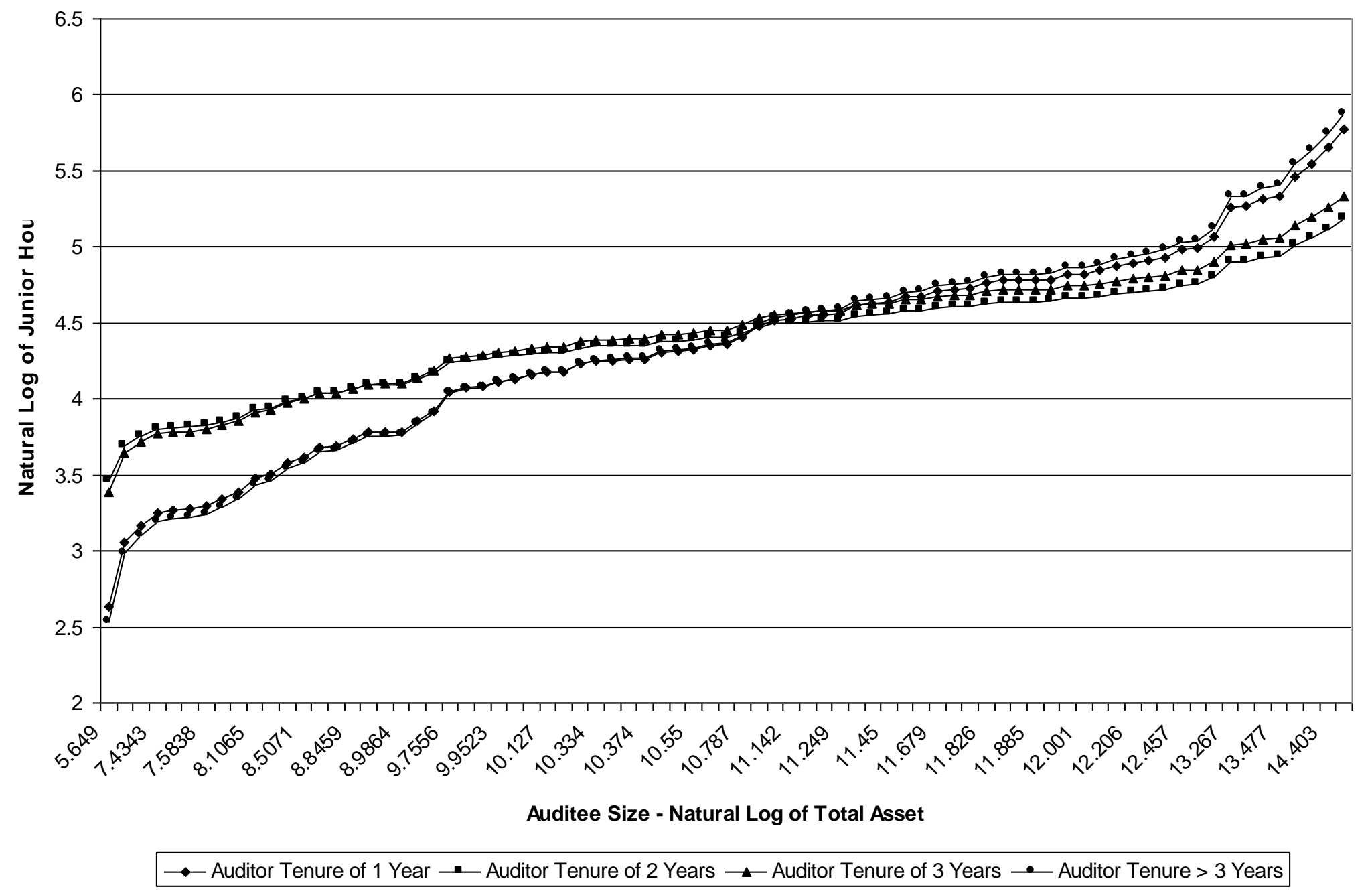


Because the general form of the algebraic derivation of response functions does not change, the calculations are not shown for audit hour equations of partners, managers, and juniors. The response functions indicate how the intercepts and slopes change for the different audit hour models as auditor tenure increases. Plots (Figures 1 through 5) of these response functions are useful in visualizing and interpreting the relations. The learning effect is very pronounced for seniors and partners, and to a lesser extent for managers and juniors, in the audits of smaller auditees. It is also interesting to note that while the response functions are sloping upwards, there is convergence, especially among the highest auditor tenure levels. In fact, it appears that for the largest auditees, firms with greater tenure have a greater number of audit hours than firms with less tenure (i.e., an inversion of the plots). This horizontal backwards S-curve may indicate that firms with more client experience can more readily recognize the need for greater audit effort for clients of greater size and complexity. The power of the statistical test for learning is enhanced using disaggregated labor hours as it appears that auditor tenure has differential influences on the different grades of professional labor.

We computed the points of intersection of the response functions (by setting them equal to one another and solving for LASSET) for each grade of professional labor, as indicated in Table 5. These points show the auditee size at which audit hours are the same for different tenure levels. The plots and calculated intersection points emphasize that the influence of auditor tenure on audit hours is dependent on client size.

Table 5

Intersection Points of Auditor Tenure Response Functions Antilog of Total Assets in Thousands ( )

Panel A: Seniors

\begin{tabular}{|c|c|c|c|}
\hline & AUDT > 3 & AUDT3 & AUDT2 \\
\hline AUDT1 & $\begin{array}{c}9.63 \\
(15,214)\end{array}$ & $\begin{array}{c}9.01 \\
(8,221)\end{array}$ & $\begin{array}{c}5.24 \\
(190) \\
\end{array}$ \\
\hline AUDT2 & $\begin{array}{c}10.84 \\
(50,990) \\
\end{array}$ & $\begin{array}{c}10.30 \\
(29,829) \\
\end{array}$ & \\
\hline AUDT3 & $\begin{array}{c}13.03 \\
(454,210)\end{array}$ & & \\
\hline \multicolumn{4}{|c|}{ Panel B: Total Audit Hours } \\
\hline \begin{tabular}{|l} 
AUDT1 \\
\end{tabular} & $\begin{array}{c}9.71 \\
(16,454)\end{array}$ & $\begin{array}{c}7.85 \\
(2,573)\end{array}$ & -- \\
\hline AUDT2 & $\begin{array}{c}10.77 \\
(47,689) \\
\end{array}$ & $\begin{array}{c}10.27 \\
(28,854) \\
\end{array}$ & \\
\hline AUDT3 & $\begin{array}{c}11.37 \\
(86,545)\end{array}$ & & \\
\hline
\end{tabular}

\begin{tabular}{|c|c|c|c|}
\hline \multicolumn{4}{|c|}{ Panel C: Partners } \\
\hline AUDT1 & $\begin{array}{c}10.17 \\
(26,220) \\
\end{array}$ & $\begin{array}{c}9.62 \\
(15,073) \\
\end{array}$ & $\begin{array}{c}9.01 \\
(8,174) \\
\end{array}$ \\
\hline AUDT2 & $\begin{array}{c}11.24 \\
(75,970)\end{array}$ & $\begin{array}{c}10.42 \\
(33,539) \\
\end{array}$ & \\
\hline AUDT3 & $\begin{array}{c}13.13 \\
(504,629) \\
\end{array}$ & & \\
\hline \multicolumn{4}{|c|}{ Panel D: Managers } \\
\hline AUDT1 & $\begin{array}{c}11.61 \\
(110,022) \\
\end{array}$ & $\begin{array}{c}9.83 \\
(18,583) \\
\end{array}$ & $\begin{array}{c}9.82 \\
(18,424) \\
\end{array}$ \\
\hline AUDT2 & $\begin{array}{c}15.31 \\
(4,478,572) \\
\end{array}$ & $\begin{array}{c}9.71 \\
(16,552) \\
\end{array}$ & \\
\hline AUDT3 & $\begin{array}{c}14.67 \\
(2,355,188)\end{array}$ & & \\
\hline \multicolumn{4}{|c|}{ Panel E: Juniors } \\
\hline AUDT1 & $\begin{array}{c}10.09 \\
(24,123) \\
\end{array}$ & $\begin{array}{c}11.40 \\
(89,732) \\
\end{array}$ & $\begin{array}{c}10.97 \\
(57,986) \\
\end{array}$ \\
\hline AUDT2 & $\begin{array}{c}10.86 \\
(52,029) \\
\end{array}$ & $\begin{array}{c}8.68 \\
(5,884) \\
\end{array}$ & \\
\hline AUDT3 & $\begin{array}{c}11.22 \\
(74,287) \\
\end{array}$ & & \\
\hline
\end{tabular}




\section{COLLINEARITY DIAGNOSTICS AND FURTHER TESTS OF ALTERNATIVE MODEL SPECIFICATIONS}

Some collinearity was induced into the models when both main effect and interaction terms were added simultaneously. The variance inflation factors (VIFs) for the auditor tenure and auditor tenure by size interaction variables ranged from 34 to 55. The VIFs for all other variables remained below 2.45. According to Neter et al. $(1983,392)$, a VIF in excess of 10 may indicate that multicollinearity is unduly influencing the least squares estimates.

To explore this possibility, collinearity diagnostics were produced by the SAS program. An examination of the condition indices and the regression coefficient variance-decomposition matrix provided no evidence that collinearity is a problem. Condition indices represent the collinearity of combinations of variables in the data. When the condition indices are large, the data is said to be ill-conditioned. According to Hair et al. $(1995,153)$, the threshold value is usually in a range of 15 to 30, with 30 being the most commonly used value. A collinearity problem is indicated when a condition index exceeds the threshold value and it accounts for a substantial portion of the variance (.90 or above) for two or more coefficients (Hair et al. 1995, 153). The SAS procedure generated 21 condition indices for each model with only three exceeding the threshold value of 15 (only one exceeding 30 ); of the three only one explained $92 \%$ of the variance of the coefficient for the log of assets. Since that index has only a single value (the coefficient of log of assets) associated with it, no collinearity is indicated. Thus, based on this analysis the data is not considered to be ill-conditioned nor is the collinearity suggested by the VIFs unduly influencing the regression results.

To satisfy ourselves further that the collinearity suggested (by the VIFs) was not driving the results, we performed an orthogonal regression procedure which uses the Gentleman-Givens method (Gentleman 1972A; Beaton et al. 1976). ${ }^{11}$ When severe multicollinearity is present in the data, this procedure can produce more accurate estimates of statistical standard error than other regression procedures. The results of the Orthoreg procedure are identical to those reported for PROC REG and PROC GLM in this study.

Other alternative specifications of the model provided evidence of robustness of the results. The results remained substantially unchanged when: 1) assets were not transformed using the natural $\log$, 2) the natural $\log$ of assets was removed from the right-hand side of the equation and used to deflate the log of audit hours on the lefthand side, and 3) the natural log of assets was transformed further by subtracting its mean. The latter method of expressing an independent variable as a deviation around its mean has been used in polynomial regression models to reduce the multicollinearity substantially and tends to avoid computational difficulties (Neter et al. 1983, 301).

\section{SUMMARY, CONCLUSION, AND LIMITATIONS}

This paper investigates the unexpected result reported by O'Keefe et al. (1994) and Stein et al. (1994) that no evidence of auditor learning was found with respect to the number of hours required to complete an audit. We were able to replicate the results of their models, after which we ran a model specified to take into account the restrictions and requirements of our data. The results of this model indicate some differential auditor learning among partners, managers, and seniors in audits of smaller clients. However, the evidence is not compelling enough to conclude differently from prior research, given only a modest degree of improvement in explanatory power. Therefore, from an economic perspective the statistically significant results do not equate to a substantial impact of audit firm tenure on audit hours.

Because of limited observations per industry in our sample, industry effects may not be reliably controlled. This could possibly result in an omitted variable problem causing the tenure measures to have biased coefficients. Nevertheless, the omitted variable problem may be mitigated by the fact that the observations are well dispersed across industries, with no concentration of audits in any particular industry. While the diverse data should work against finding significant results, its heterogeneity may increase the risk that the model is not properly specified. We tested for systematic industry effects of financials and utilities to later drop these variables due to insignificance and concern for overfitting the models. 
A potential limitation of this study is that the small number of observations per auditor tenure level for one to three years may not render stable response functions. Notwithstanding this data limitation, the replication of Stein et al. (1994) and O'Keefe et al. (1994) provides evidence of comparability and reliability of our samples, although Stein et al. and O'Keefe et al. papers were based on larger samples drawn from one international firm. Consistent with the findings of these authors, our model highlights the importance of the three client factors of size, complexity, and risk in the audit production function. We initially included indicator variables to control for systematic differences among audit firms' production functions; however, given that our sample consists of only international auditors, firm indicator variables were eventually dropped. The basis for this alternative specification is supported by literature that international firms are similar in respect to audit methodology and quality. Results remain substantially unchanged between alternative treatments.

An interesting aspect of learning that we were not able to investigate relates to turnover of staff during the first few years of an audit. We would expect the highest turnover to occur with junior staff, reduced turnover for seniors and managers, and very little turnover for partners over the first three or four years of an audit. We considered that the effect of individual auditor tenure as apposed to the effect of firm level tenure would have been a more interesting question, however our communication with contacts at firms suggested that the response rate would have been minimal given time consumption and cost of data collection.

Future research may consider investigating differences in learning curves between small and large audit client subsamples given the inverted plots of response functions for the auditor tenure by auditee size interaction effect found. Also, a longitudinal approach taking into account changes in client size, risk, complexity, and audit technology could provide further insight not available in a cross-sectional analysis.

\section{DATA AVAILABILITY}

Because of the proprietary nature of data from accounting firms, only summary data may be obtained.

\section{ACKNOWLEDMENTS}

We are thankful for comments and suggestions of Karen Pincus, Bill Wright, anonymous reviewers on earlier drafts, and colloquium participants at the University of Arkansas and Ohio University. We also gratefully acknowledge the research and econometrics assistance of Darryl Wilson and Ali Comelekoglu, and the statistical advice provided by Joe Ryan.

\section{REFERENCES}

1. Ashton, R., J. Willingham, and R. Elliott. 1987. An Empirical Analysis of Audit Delay. Journal of Accounting Research. 25 (Autumn): 275-292.

2. Bamber, E., L. Bamber, and M. Schoderbek. 1993. Audit Structure and Other Determinants of Audit Report Lag: An Empirical Analysis. Auditing: A Journal of Practice \& Theory 12 (Spring): 1-23.

3. Barefield, R., J. Gaver, and T. O'Keefe. 1993. Additional Evidence on the Economics of Attest: Extending Results from the Audit Market to the Market for Compilations and Reviews. Auditing: A Journal of Practice \& Theory 12 (Spring): 74-87.

4. Beaton, A., D. Rubin, and J. Barone. 1976. The Acceptability of Regression Solutions: Another Look at Computational Accuracy. Journal of the American Statistical Association 71 (March): 158-168.

5. Behn, B., J. Carcello, D. Hermanson, and R. Hermanson. 1999. Client Satisfaction and Big 6 Audit Fees. Contemporary Accounting Research 16 (Winter): 587-608.

6. Belsley, D., E. Kuh, and R. Welsch. 1980. Regression Diagnostic: Identifying Influential Data and Sources of Collinearity. New York, NY: John Wiley \& Sons.

7. Copley, P., M. Doucet, and K. Gaver. 1994. A Simultaneous Equations Analysis of Quality Control Review Outcomes and Engagement Fees for Audits of Recipients of Federal Financial Assistance. The Accounting Review 69 (January): 244-256. 
8. Craswell, A., and J. Francis. 1999. Pricing Initial Audit Engagements: A Test of Competing Theories. The Accounting Review 74 (April): 201-216.

9. Cullinan, C. 1998. Evidence of Non-Big 6 Market Specialization and Pricing Power in a Nice Assurance Service Market. Auditing: A Journal of Practice \& Theory 17 (Supplement): 47-57.

10. Gentleman, W. 1972a. Basic Procedures for Large, Sparse or Weighted Least Squares Problems. University of Waterloo Report CSRR-2062. Waterloo, Ontario, Canada.

11. Gentleman, W. 1972b. Least Squares Computations by Givens Transformations without Square Roots. University of Waterloo Report CSRR-2062 Waterloo, Ontario, Canada.

12. Gist, W. 1994. Empirical Evidence on the Effect of Audit Structure on Audit Pricing. Auditing: A Journal of Practice \& Theory 13 (Fall): 25-40.

13. Goldfeld, S., and R. Quandt. 1965. Some Tests for Homoscedasticity. Journal of the American Statistical Association (June): 539-547.

14. Hair, J., R. Anderson, R. Tatham, and W. Black. 1995. Multivariate Data Analysis. New Jersey: Prentice Hall.

15. Neter, J., W. Wasserman, and M. Kutner. 1983. Applied Linear Regression Models. Illinois: Richard D. Irwin.

16. O'Keefe, T., D. Simunic, and M. Stein. 1994. The Production of Audit Services: Evidence from a Major Public Accounting Firm. Journal of Accounting Research 32 (Autumn): 241-261.

17. Palmrose, Z.-V. 1983. The Pricing of Audit Services: Industry Differences and Other Insights. Proceedings of the 1983 DePaul University Research Symposium (Chicago, ILL): 47-84.

18. Palmrose, Z.-V. 1986. Audit Fees and Auditor Size: Further Evidence. Journal of Accounting Research 24 (Spring): $97-110$.

19. Simon, D., and J. Francis. 1988. The Effects of Auditor Change on Audit Fees: Tests of Price Cutting and Price Recovery. The Accounting Review 63 (April): 255-269.

20. Simunic, D. 1980. The Pricing of Audit Services: Theory and Evidence. Journal of Accounting Research 18 (Spring): 161-190.

21. Stein, M., D. Simunic, and T. O'Keefe. 1994. Industry Differences in the Production of Audit Services. Auditing: A Journal of Practice \& Theory 13 (Supplement): 128-142.

22. Walker, P., and J. Casterella. 2000. The Role of Auditee Profitability in Pricing New Audit Engagements. Auditing: A Journal of Practice \& Theory 13 (Spring): 157-167.

23. Ward, D., R. Elder, and S. Kattelus. 1994. Further Evidence on the Determinants of Municipal Audit Fees. The Accounting Review 69 (April): 399-411.

\section{ENDNOTES}

\footnotetext{
${ }^{1}$ Journal of Accounting Research, The Accounting Review, Contemporary Accounting Research, Auditing: A Journal of Practice \& Theory, Accounting Horizons, Journal of Accounting Literature.

${ }^{2}$ As discussed in the research design section, the natural logarithm transformation is used to linearize the relation between client size and labor hours as well as to correct for heteroscedasticity.

${ }^{3}$ The data gathering form may be requested from the authors.

4 The audits appear to be well dispersed across the industries represented in the sample. Indicator variables for financial institutions and utilities were considered in the preliminary models and later dropped due to their insignificant contribution and concern for over-fitting of the models.

${ }^{5}$ Because we did not control the gathering of the information, we have no way of ensuring that a random sample was in fact achieved.

${ }^{6}$ This compares to a range from $\$ 1.2$ million to $\$ 9,769.4$ million (with a mean of $\$ 488.7$ million) for financial services audits, and a range from $\$ .1$ million to $\$ 5,408$ million (with a mean of $\$ 151.8$ million) for industrial audits in the sub-samples used by Stein et al. (1994).

${ }^{7}$ A third empirical model considered by O'Keefe et al., which has been widely used in the audit fee literature, was also run in the present study:
}

$$
\operatorname{Ln} h_{j}=B_{j 0}+B_{j 1} X+B_{j 2} \ln A+\sum_{i=3}^{k} B_{j i} Y_{i}
$$


As with the second empirical model discussed in the main text of the paper, this model does not weight client size as the primary independent variable in the audit production function. That is, all other client characteristics are treated as equally important as client size. This model is different from the second empirical model in that all other client characteristics measured in continuous form are not transformed using the natural logarithm.

${ }^{8}$ The Stein et al. study is based on 108 audits and the O'Keefe et al. study is based on 246 audits.

${ }^{9}$ Because the Goldfeld-Quandt test (see Goldfeld and Quandt 1965) indicated a violation of the constant variance assumption (for both restricted and full models) prior to transforming the data, the natural log transformation is used to correct for heteroscedasticity. The more fundamental reason for using the log transformation is to linearize the relation between labor hours and client size. Also, multicollinearity does not appear to be a problem as evidenced by variance inflation factors (not shown) which did not exceed 2.45 in any equations prior to adding both auditor tenure main effect and interaction variables simultaneously. After these variables are considered together in the models, some collinearity is observed among them. Since the interaction variable is a function of the auditor tenure variable, this result is not unexpected. Although we address the collinearity issue later in the paper, this collinearity should work against finding significant results for the auditor tenure variables since the variance of the coefficients would be inflated. Collinearity diagnostics and alternative model specifications are examined in the next section to ensure that the collinearity is not driving the results.

${ }^{10}$ No influential outliers were detected using the DFFITS statistic. Belsley et al. (1980, p. 28)

suggests that DFFITS values exceeding $2 \sqrt{ }(p+1) / n$, where $p$ is the number of independent variables and $n$ is the number of observations in the data set, provide a convenient criterion for identifying suspected outliers. Based on this criterion, one audit with auditor tenure greater than four years appeared to be a suspected outlier. When this observation was dropped from the analysis the results remained unchanged. Hence, this data point was not influential.

11 The Gentleman-Givens procedure transforms the variance/covariance matrix such that the independent variables are uncorrelated. Orthogonal decomposition based on this transformation

(plane rotation) is as accurate as any other orthogonal decomposition method (Gentleman 1972a, 1972b).

\section{NOTES}




\section{NOTES}

